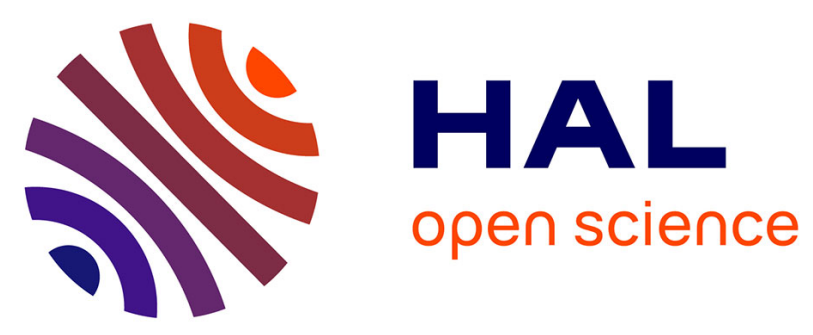

\title{
Fault Tolerant Control in a Semi-active Suspension
}

Juan C. Tudon-Martinez, Rubén Morales-Menéndez, Ricardo A. Ramirez-Mendoza, Olivier Sename, Luc Dugard

\section{To cite this version:}

Juan C. Tudon-Martinez, Rubén Morales-Menéndez, Ricardo A. Ramirez-Mendoza, Olivier Sename, Luc Dugard. Fault Tolerant Control in a Semi-active Suspension. SAFEPROCESS 2012 - 8th IFAC Symposium on Fault Detection, Supervision and Safety for Technical Processes, Aug 2012, Mexico City, Mexico. pp.1173-1178, 10.3182/20120829-3-MX-2028.00247 . hal-00939970

\section{HAL Id: hal-00939970 https://hal.science/hal-00939970}

Submitted on 31 Jan 2014

HAL is a multi-disciplinary open access archive for the deposit and dissemination of scientific research documents, whether they are published or not. The documents may come from teaching and research institutions in France or abroad, or from public or private research centers.
L'archive ouverte pluridisciplinaire HAL, est destinée au dépôt et à la diffusion de documents scientifiques de niveau recherche, publiés ou non, émanant des établissements d'enseignement et de recherche français ou étrangers, des laboratoires publics ou privés. 


\title{
Fault Tolerant Control in a Semi-active Suspension
}

\author{
Juan C. Tudón-Martínez* Ruben Morales-Menendez* \\ Ricardo Ramírez-Mendoza* Olivier Sename** Luc Dugard ** \\ * Tecnológico de Monterrey, Av. E. Garza Sada 2501, 64849, \\ Monterrey N.L., México (e-mail: \{jc.tudon.phd.mty, rmm, \\ ricardo.ramirez\}@itesm.mx) \\ ** GIPSA-lab, Control Systems Dept. CNRS-Grenoble INP, ENSE3, \\ BP 46, F-38402 St Martin d'Hres cedex, France (e-mail: \\ \{olivier.sename, luc.dugard \}@gipsa-lab.grenoble-inp.fr)
}

\begin{abstract}
A Fault Tolerant Control System (FTCS) in a Quarter of Vehicle $(Q o V)$ model is proposed. The control law is time-varying using a Linear Parameter-Varying $(L P V)$ based controller, which includes two scheduling parameters. One parameter for monitoring the nonlinear behavior of the damper, and another for fault accommodation using a reference model obtained by a state observer of the normal operating regime. The $Q_{o} V$ model represents a semi-active suspension, including an experimental magneto-rheological damper model. The $F T C S$ is analyzed when the velocity sensor fails abruptly and the $Q o V$ model is susceptible to disturbances in the road profile. Simulation results show the effectiveness of the FTCS in terms of vehicle comfort, suspension deflection and road holding in comparison with a conventional $L P V$ based control system. In the FTCS, the comfort index based on the power spectral density is within the desirable bound (1.8) in all range of frequencies, once the sensor fault has occurred; while, the conventional control system deteriorates the comfort $54 \%$, specially at low frequencies (0-4 Hz). Additionally, the FTCS improves the road holding and suspension deflection indexes, $33 \%$ and $39 \%$ respectively, when the fault accommodation is considered.
\end{abstract}

Keywords: Fault-tolerant control, Fault diagnosis, Sensor faults, Semi-active suspension, Automotive control.

\section{INTRODUCTION}

In modern and advanced technological systems, such as automotive industry, it is necessary to design control systems that consider features of safety and fault tolerance in order to improve the process reliability, Patton (1997). The main objective of a Fault Tolerant Control System (FTCS $)$ is to maintain the process performance close to its nominal value and to ensure global stability in the presence of process/instrument failures. A generalized structure of an FTCS can be reviewed in Blanke et al. (2006). Reviews on FTCS (Patton (1997), Jiang (2005), Zhang and Jiang (2008)) present a global classification based on two major groups: those approaches that are designed off-line in robust form, named passive FTCS, and those that are based on an automatic control reconfiguration mechanism, named active FTCS.

When the number of fault scenarios increases, the passive $F T C S$ can result very conservative and the overall controller performance becomes less and less effective for each fault; whereas, the active FTCS does not have this drawback, Jiang (2005). The control law in the active FTCS demands a reliable Fault Detection and Isolation (FDI) system and an effective reconfigurable control scheme.

\footnotetext{
* Authors thank to Tecnológico de Monterrey (Autotronics research chair) and CONACyT (PCP 03/2010) for their partial support.
}

The reconfiguration mechanism of switching is used in the Linear Parameter-Varying $(L P V)$ controller, while Model Reference Adaptive Control $(M R A C)$ is classified as a tracking mechanism, according to Zhang and Jiang (2008). The control theory based on reference models and $L P V$ systems is gaining importance in FTCS since last decade. For instance, the performance of active and pasive faulttolerant $L P V$ based control have similar performances according to Sloth et al. (2010). An FTCS is proposed for polytopic $L P V$ systems in Rodrigues et al. (2007), the closed-loop stability under multiple failures is established using a Linear Matrix Inequality $(L M I)$. In Abdullah and Zribi (2009), a model reference control for $L P V$ systems is proposed; however, the controller is not designed to accommodate faults. Similarly, Vargas-Martínez et al. (2010) and Miyasato (2006) proposed an $M R A C$ for an $L P V$ system using a robust $H_{\infty}$ controller.

In semi-active suspension control systems for vehicles, many researches are focused to improve the vehicle comfort, ensuring its safety and stability. A comparative research in semi-active control strategies for a MagnetoRheological $(M R)$ suspension is presented in Dong et al. (2010), the sliding mode controller shows the best performance under different road profiles; however, a fuzzy controller has a best road holding. In Savaresi and Spelta (2007), a mixed control based on Sky-Hook $(S H)$ and Acceleration Driven Damping $(A D D)$ framework is proposed 
for semi-active dampers, the $S H$ - $A D D$ has good comfort performance; however, an innovative controller based on a single-sensor layout, proposed in Spelta et al. (2010), is better in comfort than $S H$, and similar to $S H-A D D$. Based on robust control theory, an $L P V$ controller is synthesized to improve the passenger comfort while keeping the road holding index by using an $M R$ suspension, Do et al. (2010).

The aforementioned approaches have better performance in comfort than a passive suspension; however, none of them consider the inherent faults in process instrumentation. Otherwise, in a full-vehicle active suspension system, an FTCS based on sliding mode theory is proposed by Chamseddine and Noura (2008), good simulation results in an exhaustive analysis are obtained. In Bosche et al. (2009), an FTCS for vehicle dynamics is proposed, but the robust controller can not diagnose the faulty component. An FTCS on an active suspension system is presented in Yetendje et al. (2007), a set of unknown input observers is proposed to diagnose faults and a linear quadratic regulator is synthesized for each faulty condition. A methodology for controlling the damping ratio of dampers based on estimation of parameters is proposed in Fischer and Isermann (2004), the estimated damper model is used to create a fault signature using parity equations; however, the detected fault is not compensated. In Gáspár et al. (2010), an FTCS based on $L P V$ control is proposed to guarantee road holding and roll stability in a vehicle model when sensor and actuator faults appear.

This paper proposes an active FTCS for a semi-active suspension of a Quarter of Vehicle $(Q o V)$ which includes an experimental $M R$ damper model. The proposed FTCS is based on the $L P V$ control theory oriented to comfort, by using 2 varying parameters. One for indicating the nonlinearities of the damper, and another one for the fault accommodation using a reference model. The FDI module, based on residual generation, provides a scheduling parameter to the $L P V$ controller in order to accommodate the fault. The performance of the FTCS is compared with a conventional $L P V$ controller when sensors of the process fail abruptly.

The outline of this paper is as follows: in the next section, the $Q o V$ model with an $M R$ damper is described. Section 3 presents the proposed FTCS. Section 4 shows the simulation tests. A discussion of results is shown in section 5 . Finally, conclusions are presented in section 6 .

\section{2. $\mathrm{Q}_{O} \mathrm{~V}$ MODEL USING AN MR DAMPER}

An experimental $M R$ damper model represents the suspension between both masses, Fig. 1. It is assumed that the wheel-road contact is ensured. All variables are described in Table 1.

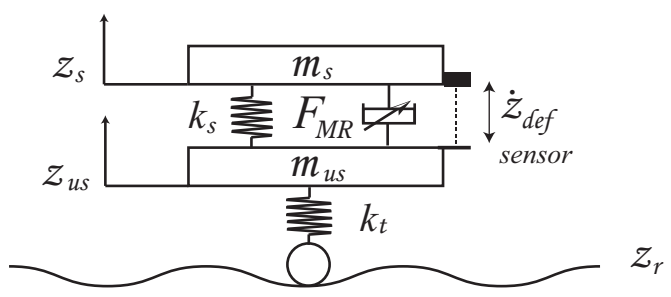

Fig. 1. Model for a $Q o V$ with a semi-active damper.
Table 1. Definition of Variables.

\begin{tabular}{|c|c|}
\hline Variable & Description \\
\hline$c_{f}$ & Friction coefficient of the $M R$ fluid \\
$c_{\text {control }}$ & Maximum value in the controller output \\
$c_{M R}$ & $M R$ damping coefficient \\
$c_{p}$ & Passive damping coefficient \\
$c_{v}$ & Viscosity coefficient of the $M R$ fluid \\
$c_{y}$ & Elasticity coefficient of the $M R$ fluid \\
$F_{M R}$ & $M R$ damping force \\
$I$ & Electric current \\
$I_{m a x}$ & Maximum electric current allowed \\
$K_{o}$ & Observer feedback gain \\
$k_{s}$ & Spring stiffness coefficient \\
$k_{t}$ & Stiffness coefficient of the wheel tire \\
$m_{s}$ & Sprung mass in the $Q o V$ \\
$m_{u s}$ & Unsprung mass in the $Q o V$ \\
$u_{s a t}$ & Filtered and bounded controller output \\
$\dot{z}_{\infty}$ & Absolute of maximum $\dot{z}_{\text {def }}$ in the last $k$ samples \\
$\dot{z}_{\text {z }} \dot{z}_{d e f}$ & Damper piston velocity (deflection velocity) \\
$\dot{z}_{d e f r}$ & Deflection velocity of the reference model \\
$z_{r}$ & Road profile (input disturbance) \\
$z_{s}$ & Vertical position of the mass $m_{s}$ \\
$\dot{z}_{s}$ & Vertical velocity of the mass $m_{s}$ \\
$\ddot{z}_{s}$ & Vertical acceleration of the mass $m_{s}$ \\
$z_{u s}$ & Vertical position of the mass $m_{u s}$ \\
$\dot{z}_{u s}$ & Vertical velocity of the mass $m_{u s}$ \\
$\ddot{z}_{u s}$ & Vertical acceleration of the mass $m_{u s}$ \\
$\rho$ & Varying parameter for the $M R$ damper hysteresis \\
$\rho_{f}$ & Scheduling parameter for the fault accomodation \\
$\rho_{s a}$ & Scheduling parameter for the current saturation \\
$\rho_{s a t}$ & Scheduling parameter for representing the \\
& hysteresis and saturation of the $M R$ damper \\
\hline
\end{tabular}

The system dynamics is given by:

$$
\begin{aligned}
m_{s} \ddot{z}_{s} & =-k_{s}\left(z_{s}-z_{u s}\right)-F_{M R} \\
m_{u s} \ddot{z}_{u s} & =k_{s}\left(z_{s}-z_{u s}\right)-k_{t}\left(z_{u s}-z_{r}\right)+F_{M R}
\end{aligned}
$$

The $M R$ damper model embedded in the $Q o V$ is based on Do et al. (2010). The saturation and hysteresis of the $M R$ damper is included into the parameter $\rho_{\text {sat }}(3)$; where, $\rho$ describes the $M R$ phenomenon by a viscous, elasto-plastic, and friction coefficient and $\rho_{s a}$ is the saturated controller output. Thus, the semi-active $M R$ damping force is:

$$
\begin{aligned}
F_{M R} & =c_{M R} \cdot I_{\max } \cdot \rho_{\text {sat }}+c_{p} \cdot \dot{z} \\
\rho_{\text {sat }} & =\rho \cdot \rho_{\text {sa }} \\
\rho_{\text {sa }} & =\tanh \left(I / c_{\text {control }}\right) \\
\rho & =c_{v} \dot{z}+c_{y} \frac{\dot{z}}{\dot{z}_{\infty}}+c_{f} \operatorname{sign}(\dot{z}) \tanh \left(\frac{100}{|(|\dot{z}|-100)|}\right)(5) \\
\dot{z}_{\infty} & =\|(|\dot{z}|)\|_{\infty_{i-k}}^{i}=\sup \left\{\dot{z}_{i-k} \ldots \dot{z}_{i}\right\}
\end{aligned}
$$

Since $I$ is always positive, the model includes the sign function of $\dot{z}=\dot{z}_{\text {def }}=\left(\dot{z}_{s}-\dot{z}_{u s}\right)$ into the parameter $\rho$ for representing the jounce/rebound effects of the damper. A general state-space representation of the $Q o V$ model can be obtained, rewriting (1) and (2) as:

$$
\begin{aligned}
\dot{x}_{s} & =A_{s} \cdot x_{s}+B_{s} \cdot u+B_{s 1} \cdot z_{r} \\
y & =C_{s} \cdot x_{s}+D_{s}\left[\begin{array}{c}
u \\
z_{r}
\end{array}\right]+\eta(t)
\end{aligned}
$$

where $\eta$ is an abrupt sensor fault (gain, bias, breakdown, offset or freeze), $u$ is the saturated controller output and,

$$
y=\dot{z}_{\text {def }}, C_{s}=\left[\begin{array}{llll}
0 & 1 & 0 & -1
\end{array}\right], D_{s}=\left[\begin{array}{ll}
0 & 0
\end{array}\right]
$$




$$
\begin{gathered}
B_{s}=\left[\begin{array}{c}
0 \\
\frac{-c_{M R} \cdot \rho}{m_{s}} \\
0 \\
\frac{c_{M R} \cdot \rho}{m_{u s}}
\end{array}\right], B_{s 1}=\left[\begin{array}{c}
0 \\
0 \\
0 \\
\frac{k_{t}}{m_{u s}}
\end{array}\right], x_{s}=\left[\begin{array}{c}
z_{s} \\
\dot{z}_{s} \\
z_{u s} \\
\dot{z}_{u s}
\end{array}\right] \\
A_{s}=\left[\begin{array}{cccc}
0 & 1 & 0 & 0 \\
\frac{-k_{s}}{m_{s}} & \frac{-c_{p}}{m_{s}} & \frac{k_{s}}{m_{s}} & \frac{c_{p}}{m_{s}} \\
0 & 0 & 0 & 1 \\
\frac{k_{s}}{m_{u s}} \frac{c_{p}}{m_{u s}} & \frac{-k_{s}-k_{t}}{m_{u s}} \frac{-c_{p}}{m_{u s}}
\end{array}\right], u=I_{\max } \rho_{s a}
\end{gathered}
$$

\section{FAULT-TOLERANT CONTROL DESIGN}

In the $Q o V$ system defined by (7), it is assumed that $\dot{z}_{\text {def }}$ is measured by a linear velocity sensor, Fig. 1. Figure 2 shows a block diagram of the FTCS approach; the controller inputs are $\dot{z}_{\text {def }}$ and 2 varying parameters: $\rho_{\text {sat }}^{*}$ includes the nonlinearities of the damper and $\rho_{f}$ quantifies the fault by using a reference model of the $Q_{o V} V$. The fault is implemented in additive form, called soft fault.

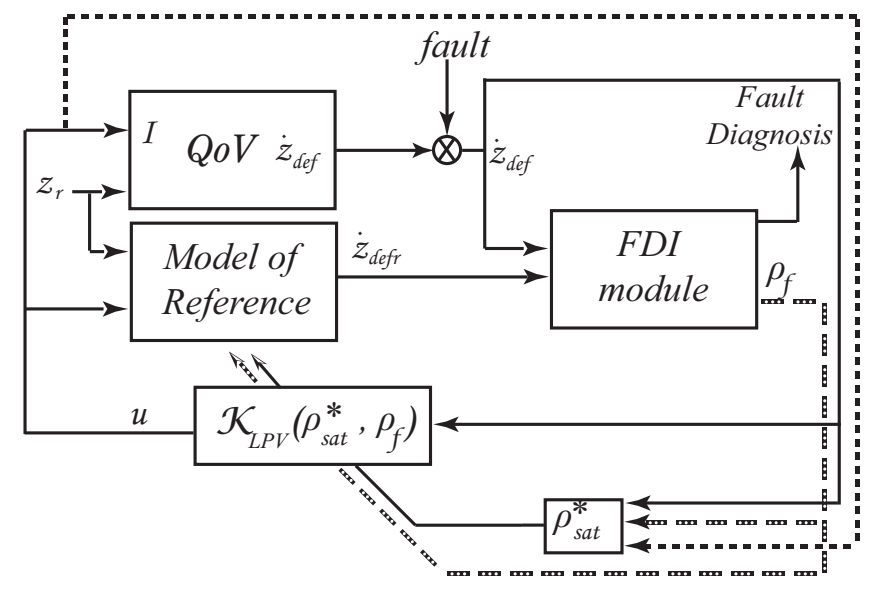

Fig. 2. Proposed FTCS structure applied on a $Q o V$.

\subsection{FDI using a reference model}

The FDI module is based on a residual generation. The reference model (baseline process) was obtained by a state observer in the overall operating regime of the process, by including the nonlinearities of the $M R$ damper:

$$
\begin{aligned}
\dot{\tilde{x}}_{s} & =A_{s} \cdot \tilde{x}_{s}+B_{s} \cdot u+B_{s 1} \cdot z_{r}+K_{o}(y-\hat{y}) \\
\hat{y} & =C_{s} \cdot \tilde{x}_{s}=\dot{z}_{\text {def } r}
\end{aligned}
$$

where, $K_{o}$ is the observer feedback matrix used to reduce the differences between the reference model and the process. The pole placement method is used to find $K_{o}$ which guarantees the convergence speed and observer stability.

The residual $r$ is computed as: $r=\dot{z}_{\text {defr }}-\dot{z}_{\text {def }}$. When the residual is close to zero, the process is free of faults, while any change in $r$ represents a faulty scheme. In the FDI module, $\rho_{f}$, which is bounded and available online, is generated to achieve the fault accommodation by including any faulty scheme in the control system. In (9), $\epsilon$ is a constant different to zero used to avoid ambiguities, by assuming a resolution in $\dot{z}_{\text {def }}$ of $1 \mathrm{~mm} / \mathrm{s}, \epsilon=1 \times 10^{-4}$.

$$
\rho_{f}=\frac{\dot{z}_{\text {defr }}+\epsilon}{\dot{z}_{\text {def }}+\epsilon} \in[-4,4]
$$

$\rho_{f}$ expresses the ratio between the desired deflection velocity and the measured signal; its range (peak to peak) is defined by simulation with different faults. If $\dot{z}_{d e f r}$ is higher than the measurement, $\rho_{f}$ will be the factor that must multiply the failed signal $\dot{z}_{\text {def }}$ in (17) for accommodating the fault. If the velocity sensor is free of faults, $\rho_{f}=1$, the $M R$ force is obtained in normal form. False positives and negatives strongly depend on the accuracy of the reference model; thus, it is necessary to use a reliable model in order to have a low false alarm rate. Using $\rho_{f}$ defined in (9), $A_{s}$ and $\rho$ are rewritten as:

$$
\begin{gathered}
A_{s}\left(\rho_{f}\right)=\left[\begin{array}{cccc}
0 & 1 & 0 & 0 \\
\frac{-k_{s}}{m_{s}} & \frac{-c_{p} \cdot \rho_{f}}{m_{s}} & \frac{k_{s}}{m_{s}} & \frac{c_{p} \cdot \rho_{f}}{m_{s}} \\
0 & 0 & 0 & 1 \\
\frac{k_{s}}{m_{u s}} & \frac{c_{p} \cdot \rho_{f}}{m_{u s}} & \frac{-k_{s}-k_{t}}{m_{u s}} & \frac{-c_{p} \cdot \rho_{f}}{m_{u s}}
\end{array}\right] \\
\rho\left(\rho_{f}\right)=c_{v} \dot{z} \rho_{f}+c_{y} \frac{\dot{z} \rho_{f}}{\dot{z} \rho_{f}}+c_{f} \operatorname{sign}(\dot{z}) \tanh \left(\frac{100}{\left|\left(\left|\dot{z} \rho_{f}\right|-100\right)\right|}\right)
\end{gathered}
$$

In presence of a fault, $\rho\left(\rho_{f}\right)$ will be blind to the failure because $\rho_{f}$ will accommodate the value of $\dot{z}$. Thus, $\rho_{\text {sat }}$ (3) is redefined to include the fault as:

$$
\rho_{\text {sat }}^{*}=\rho\left(\rho_{f}\right) \cdot \rho_{s a}
$$

\subsection{Synthesis of the LPV controller}

LPV Modelling. The $L P V$ structure of the $Q o V$ model can be obtained as follows. First, a low pass filter must be added to the $Q o V$ model for matching the controller actuation with the damper time response; this filter allows to build a proper model structure for the $L P V$ based controller synthesis, Poussot-Vassal et al. (2008). A filter with bandwidth of $25 \mathrm{~Hz}$ was used for ensuring the time response of the $M R$ damping force $(\sim 40 \mathrm{~ms})$ :

$$
\mathcal{F}:\left[\begin{array}{c}
\dot{x}_{f} \\
u_{f}
\end{array}\right]\left[\begin{array}{cc}
A_{f} & B_{f} \\
C_{f} \rho_{s a t}^{*} & 0
\end{array}\right]\left[\begin{array}{c}
x_{f} \\
u
\end{array}\right]
$$

Second, a saturation function must be designed as:

$$
u_{s a t}=\left\{\begin{array}{clc}
I_{\max } & \text { if } u_{f}>>I_{\max } \\
u_{f} & \text { if } 0 \leq u_{f} \leq I_{\max } \\
0 & \text { if } \quad u_{f}<<0
\end{array}\right.
$$

The filtered-saturated manipulation is approximated as,

$$
u_{M R} \cong C_{f} x_{f} \cdot \rho_{s a t}^{*} \in[0-2.5] A
$$

The new structure (16) takes into account the saturation and semi-activity of the damper in the controller output; this signal includes the varying parameter instead the matrix $B$ which only contains the filtering property. Figure 3 shows a block diagram of this new structure.

$$
\begin{gathered}
\dot{x}_{s f}=A\left(\rho_{s a t}^{*}, \rho_{f}\right) \cdot x_{s f}+B \cdot u_{M R}+\left[\begin{array}{c}
B_{s 1} \\
0
\end{array}\right] \cdot z_{r} \\
y=\left[\begin{array}{ll}
C_{s} & 0
\end{array}\right] \cdot x_{s f}+\eta(t) \\
x_{s f}=\left[\begin{array}{c}
x_{s} \\
x_{f}
\end{array}\right], A\left(\rho_{s a t}^{*}, \rho_{f}\right)=\left[\begin{array}{cc}
A_{s}\left(\rho_{f}\right) & \rho_{s a t}^{*} B_{s} C_{f} \\
0_{1 \times 4} & A_{f}
\end{array}\right], B=\left[\begin{array}{c}
0_{4 \times 1} \\
B_{f}
\end{array}\right]
\end{gathered}
$$




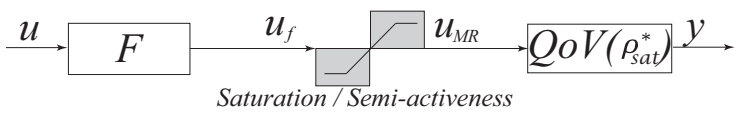

Fig. 3. $Q o V$ model with a semi-active saturated input.

Design of a Polytopic LPV Controller. The MR damping force described in (2) can be redefined by adding the scheduling parameter $\rho_{f}$ for the fault accommodation as:

$$
\begin{gathered}
F_{M R}=c_{M R} \cdot I_{\text {max }} \cdot \rho_{\text {sat }}^{*}+c_{p} \cdot \dot{z}_{d e f} \cdot \rho_{f} \\
\rho_{\text {sat }}^{*} \in[0,500]
\end{gathered}
$$

The span of $\rho_{s a t}^{*}$ is defined experimentally, Fig. 5 .

$L P V$ control theory deals with nonlinearities of the process and allows to obtain a varying controller through linear changes of the model parameters. The $L P V$ based controller can be obtained through the interpolation of a polytope whose vertices are Linear Time-Invariant $(L T I)$ controllers. The controller design is oriented to comfort assuming that the wheel-road contact is ensured.

Since the $L P V$ model of the $Q o V$ depends on 2 varying parameters defined in (9) and (12), a polytope of 4 LTI controllers is designed using the $H_{\infty}$ control framework. This robust control theory is based on the synthesis of a stable controller that minimizes the impact of the disturbance $z_{r}$ and model uncertainties on the controlled output. The $L P V$ controller is defined as an optimization problem solved by an LMI, Poussot-Vassal et al. (2008). Figure 4 describes the structure for designing the $H_{\infty}$ controller. The weighting functions, based on a priori knowledge of the performance objectives, are designed to ensure stability without performance degradation as,

$$
W_{\ddot{z}_{s}}=\frac{K_{s} \omega_{s}^{2}}{s^{2}+2 \zeta \omega_{s} s+\omega_{s}^{2}}, W_{z_{u s}}=\frac{K_{u s} \omega_{u s}}{s+\omega_{u s}}, W_{z_{r}}=3 \times 10^{-2}
$$

where $W_{\ddot{z}_{s}}$ allows to reduce the amplification of $\ddot{z}_{s}$ for

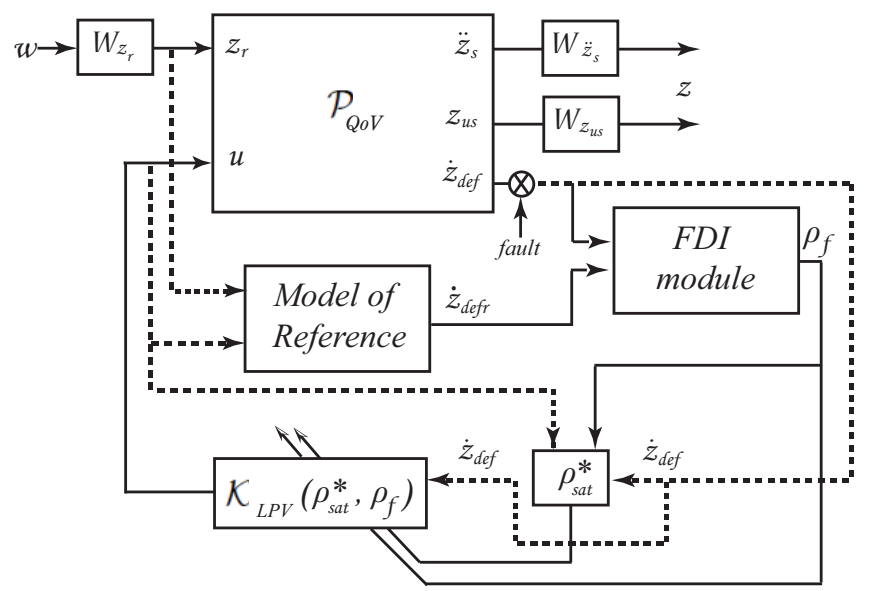

Fig. 4. $H_{\infty}$ controller for a $L T I$ model of a $Q o V$.

achieving the desired comfort, $W_{z_{u s}}$ is shaped to ensure the road holding and $W_{z_{r}}$ increases the sensitivity to the road profile. Taking into account the control specifications, the generalized system $\mathcal{P}$ for the $L P V$ control synthesis is,

$$
\begin{aligned}
\dot{x}_{s f} & =A\left(\rho_{s a t}^{*}, \rho_{f}\right) \cdot x_{s f}+B \cdot u_{M R}+\left[\begin{array}{c}
B_{s 1} \\
0
\end{array}\right] \cdot W_{z_{r}} \cdot w \\
{\left[\begin{array}{c}
\ddot{z}_{s} \\
z_{u s}
\end{array}\right] } & =C_{1}\left(\rho_{s a t}^{*}, \rho_{f}\right) \cdot x_{s f} \\
z & =\left[\ddot{z}_{s} z_{u s}\right]^{T} \cdot\left[\begin{array}{cc}
W_{\ddot{z}_{s}} & 0 \\
0 & W_{z_{u s}}
\end{array}\right]=\left[\begin{array}{ll}
\ddot{z}_{s} & z_{u s}
\end{array}\right]^{T} \cdot W \\
y & =C_{2} \cdot x_{s f}
\end{aligned}
$$

where $C_{1}\left(\rho_{s a t}^{*}, \rho_{f}\right)=\left[C_{s 1}\left(\rho_{f}\right) \rho_{s a t}^{*} D_{s 1} C_{f}\right]$ and,

$$
\begin{gathered}
D_{s 1}=\left[\begin{array}{c}
\frac{-1}{m_{s}} \\
0
\end{array}\right], C_{s 1}\left(\rho_{f}\right)=\left[\begin{array}{cccc}
\frac{-k_{s}}{m_{s}} & \frac{-c_{p} \rho_{f}}{m_{s}} & \frac{k_{s}}{m_{s}} & \frac{c_{p} \rho_{f}}{m_{s}} \\
0 & 0 & 1 & 0
\end{array}\right] \\
C_{2}=\left[\begin{array}{ll}
C_{s 2} & 0
\end{array}\right], C_{s 2}=\left[\begin{array}{llll}
0 & 1 & 0 & -1
\end{array}\right]
\end{gathered}
$$

\subsection{Hurwitz stability criterion}

For $L P V$ control synthesis, the Hurwitz criterion consists in placing poles of the closed-loop system into a region bounded by a polytope. Considering two varying parameters, the $L P V$ polytopic controller is given as,

$$
\mathcal{K}_{L P V}(\rho)=\Sigma_{i=1}^{4} \alpha_{i}\left[\begin{array}{ll}
A c_{i} & B c_{i} \\
C c_{i} & D c_{i}
\end{array}\right]
$$

where,

$$
\alpha_{i}(\rho):=\frac{\prod_{k=1}^{2}\left|\rho_{k}-\mathcal{K}\left(w_{i}\right)_{k}\right|}{\prod_{k=1}^{2}\left(\bar{\rho}_{k}-\underline{\rho}_{k}\right)}, i=1, \ldots, 4
$$

$\alpha_{i}$ is the weight of the $i$ LTI controller $\left(\Sigma_{i=1}^{4} \alpha_{i}(\rho)=1\right)$ and $\mathcal{K}\left(w_{i}\right)$ is the $i$ vertex of the polytopic system. The closed-loop system of a generalized LTI system described in (18) with a LTI controller defined in (19) is given by,

$$
G(\mathcal{P}, \mathcal{K}):\left[\begin{array}{l}
\dot{\xi} \\
z
\end{array}\right]=\left[\begin{array}{ll}
\mathcal{A} & \mathcal{B} \\
\mathcal{C} & \mathcal{D}
\end{array}\right]\left[\begin{array}{c}
\xi \\
w
\end{array}\right]
$$

where, $\xi=\left[\begin{array}{ll}x_{s f}^{T} & x_{c}^{T}\end{array}\right]$ ( $x_{c}$ is the controller state), $\mathcal{D}=0$ and,

$$
\mathcal{A}=\left[\begin{array}{cc}
A+B D_{c} C_{2} & B C_{c} \\
B_{c} C_{2} & A_{c}
\end{array}\right] \mathcal{B}=\left[\begin{array}{c}
B_{s 1} W_{z_{r}} \\
0_{2 \times 1}
\end{array}\right] \mathcal{C}=\left[\begin{array}{ll}
C_{1} W & 0_{2 \times 1}
\end{array}\right]
$$

The aim is to find a Lyapunov function $X$ that satisfies,

$$
V(\xi)=\xi^{T} X \xi
$$

where, $V$ must be positive defined; and its derivative,

$$
\dot{V}(\xi)=\xi^{T}\left(\mathcal{A}^{T} X+X \mathcal{A}\right) \xi,
$$

must be negative defined. By solving the LMIs in $X$ for each vertex of the polytopic closed-loop system, the asymptotical stability is ensured (making $\mathcal{A}$ Hurwitz).

\section{SIMULATION TESTS}

Based on the $Q o V$ model, $M R$ damper model and $L P V$ controller, several simulations were implemented. The QoV model parameters described in eqn. (1) have been identified from a commercial vehicle, Table 2.

Table 2. QoV model parameters.

\begin{tabular}{|cc|cc|}
\hline Parameter & Value & Parameter & Value \\
\hline$m_{s}$ & $387(\mathrm{Kg})$ & $m_{u s}$ & $139.5(\mathrm{Kg})$ \\
$k_{s}$ & $37,300(\mathrm{~N} / \mathrm{m})$ & $k_{t}$ & $295,200(\mathrm{~N} / \mathrm{m})$ \\
\hline
\end{tabular}

The model coefficients in the jounce and rebound effect of the shock absorber are shown in Table 3; they were identified based on a standard test (chirp of $25 \mathrm{~mm}$ of amplitude at $[0.5-15] \mathrm{Hz}$ ). Table 4 shows the parameters of the weighting functions in the controller, the cut frequencies 
Table 3. $M R$ damper model coefficients.

\begin{tabular}{|lccc|}
\hline Coefficient & $\dot{z}_{\text {def }}>0$ & $\dot{z}_{\text {def }}<0$ & units \\
\hline$c_{v}$ & 0.257 & 0.089 & $\mathrm{~s} / \mathrm{mm}$ \\
$c_{y}$ & -9.3 & 5.6 & - \\
$c_{f}$ & 0.9158 & 0.5461 & $\mathrm{~mm} / \mathrm{s}$ \\
$c_{M R}$ & 6.481 & 3.62 & $\mathrm{~N} / \mathrm{A}$ \\
$c_{p}$ & 0.8 & 0.8 & $\mathrm{Ns} / \mathrm{mm}$ \\
$c_{\text {control }}$ & 25 & 25 & - \\
$I_{\text {max }}$ & 2.5 & 2.5 & $\mathrm{~A}$ \\
$k$ & 228 & 228 & - \\
\hline
\end{tabular}

Table 4. $L P V$ controller parameters.

\begin{tabular}{|cc|cc|}
\hline Parameter & Value & Parameter & Value \\
\hline$K_{s}$ & 1 & $\omega_{u s}$ & $53.4(\mathrm{rad} / \mathrm{s})$ \\
$\zeta$ & 0.7 & $K_{u s}$ & 1 \\
$\omega_{s}$ & $15.7(\mathrm{rad} / \mathrm{s})$ & & \\
\hline
\end{tabular}

have been selected according to the resonance frequencies of the sprung $(\sim 2.5 \mathrm{~Hz})$ and unsprung mass $(\sim 8.5 \mathrm{~Hz})$.

Figure 5 (top plot) compares the damper model and experimental data generated from an $M R$ damper which has continuous actuation between 0-2.5 A with a range of damping force of $\pm 4000 \mathrm{~N}$ and stroke of $\pm 40 \mathrm{~mm}$; while bottom plot shows the $\rho_{\text {sat }}^{*}$ range.

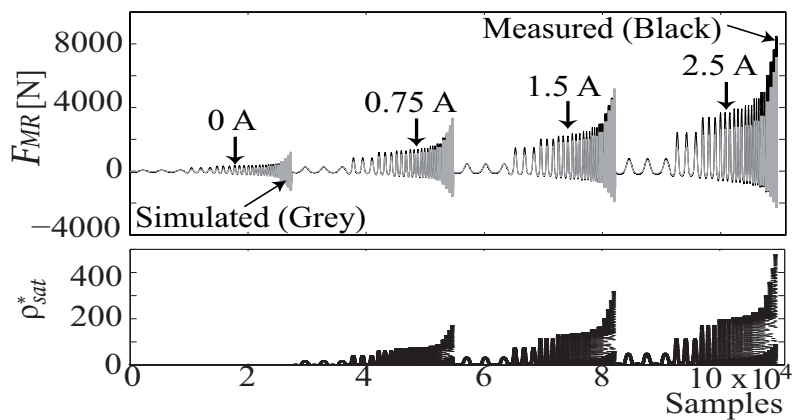

Fig. 5. Comparison of the experimental and modeled $M R$ damping force at different electric currents (top); behavior of $\rho_{\text {sat }}^{*}$ in the identification test (bottom).

The performance specification for comfort at low frequencies, [0-5] Hz, establishes that the maximum gain of the frequency response $z_{s} / z_{r}$ must be bounded by 1.8 , Poussot-Vassal et al. (2008). A human can feel dizziness and sickness caused by sudden motions. The comfort at high frequencies, [5-20] Hz, is evaluated by $\ddot{z}_{s} / z_{r}$; although human is not sensitive at this frequencies, is desirable that the gain be low. A good road holding is considered when the maximum gain of $\frac{z_{u s}-z_{r}}{z_{r}}$ is limited to 2.5 for low disturbances $\left(z_{r}<3 \mathrm{~cm}\right)$ from 0 to $20 \mathrm{~Hz}$, while the life cycle of the damper is preserved when $z_{\text {def }}$ is low.

The FTCS is compared with a conventional $L P V$ based controller in order to analyze its effectiveness when a disturbance on the road is presented and the velocity sensor fails. An abrupt sensor fault such as gain, bias, breakdown, offset or freeze has been implemented; and $z_{r}$ is a signal chirp of $2 \mathrm{~cm}$ from 0.5 to $20 \mathrm{~Hz}$. The conventional controller synthesis does not include the fault accommodation property provided by the FDI module.

\section{RESULTS AND DISCUSSION}

An abrupt fault of magnitude $4 \sigma$ is implemented in the $\dot{z}_{\text {def }}$ sensor at $t=[1.25-3.75]$ s. Figure 6 shows that the fault detection and $\rho_{f}$ computing occur simultaneously.

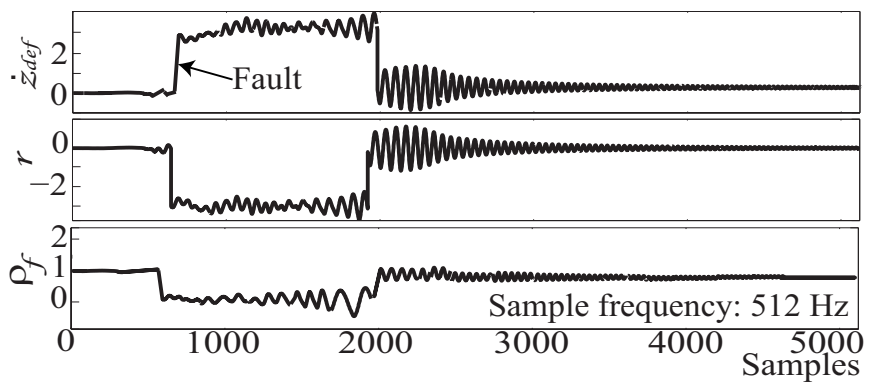

Fig. 6. Detection of a sensor fault in the $Q_{o} V$.

A pseudo-Bode plot tests the frequency response of the control system, Poussot-Vassal et al. (2008); it shows the maximum gain of the system for each excitation frequency. Figure 7 presents the frequency response of $z_{s} / z_{r}$, the conventional $L P V$ based controller shows a gain greater than the acceptable limit (1.8) at frequencies lower than $4 \mathrm{~Hz}$, while the FTCS ensures the comfort in the entire range of frequencies even a fault sensor has occurred.

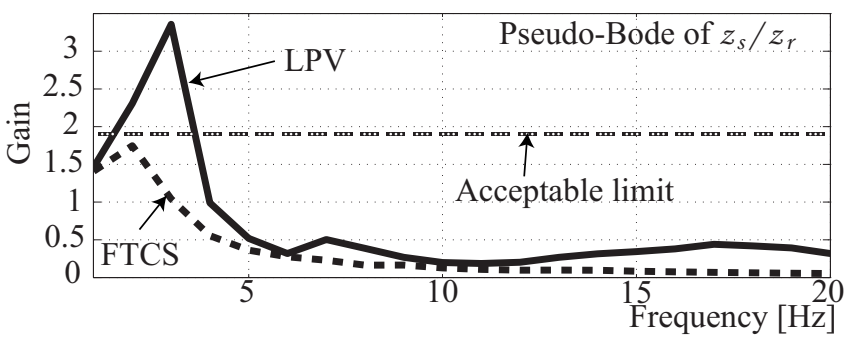

Fig. 7. Comparison of the passenger comfort index between the conventional controller and the proposed FTCS.

The acceleration of the sprung mass is also deteriorated from $0-12 \mathrm{~Hz}$ when the fault is not accommodated, mainly at the resonance frequency of $m_{s}, 2.5 \mathrm{~Hz}$, Fig. 8 .

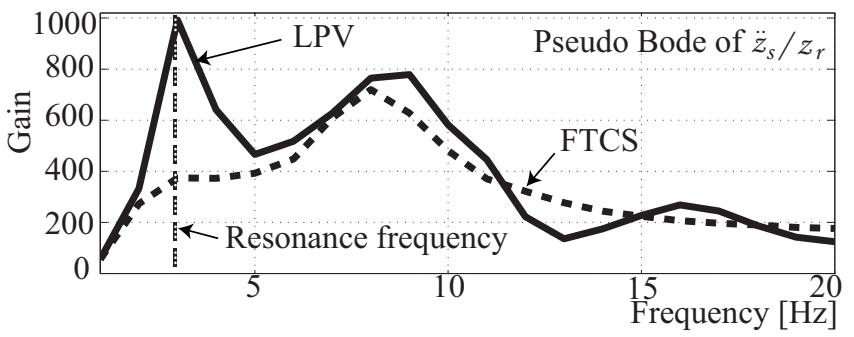

Fig. 8. Comparison of $\ddot{z}_{s}$ between both control strategies.

The road holding is analyzed in the Fig. 9. Practically, both control systems satisfy the limit (2.5); however, the $L P V$ controller shows greater gain at low frequencies (2$5 \mathrm{~Hz}$ ), i.e the wheel deflection is increased. Similarly, the suspension deflection $\left(z_{\text {def }}\right)$ is considerably bigger at low frequencies when the fault can not be accommodated; this reduces the lifetime of the shock absorber.

Table 5 shows the Root Mean Square $(R M S)$ of the variables $z_{s}, \ddot{z}_{s}, z_{u s}-z_{r}$ and $z_{\text {def }}$ for comparing the transient response of both approaches when the sensor fails. All 


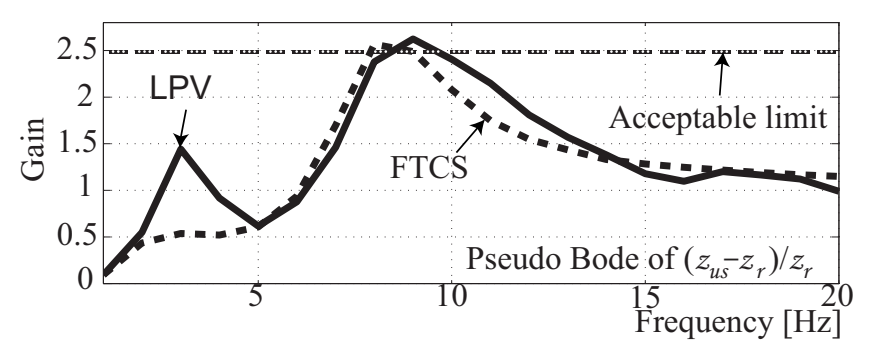

Fig. 9. $P S D$ of the road holding index in both controllers.

control objectives are better in the FTCS, specially the comfort because the $R M S$ of $z_{s}$ is reduced to $2.6 \mathrm{~cm}(54 \%)$.

Table 5. Comparison of $R M S$ index.

\begin{tabular}{|ccccc|}
\hline $\begin{array}{c}\text { Control } \\
\text { Approach }\end{array}$ & $\begin{array}{c}z_{s} \\
(\mathrm{~cm})\end{array}$ & $\begin{array}{c}\ddot{z}_{s} \\
\left(\frac{m}{s^{2}}\right)\end{array}$ & $\begin{array}{c}z_{u s}-z_{r} \\
(\mathrm{~cm})\end{array}$ & $\begin{array}{c}z_{\text {def }} \\
(\mathrm{cm})\end{array}$ \\
\hline$F T C S$ & 2.2 & 8.1 & 1.8 & 2.6 \\
$L P V$ conventional & 4.8 & 9.5 & 2.7 & 4.3 \\
\hline
\end{tabular}

If the control system presents new/unknown sensor faults, the FDI module must be capable to detect this failure since any deviation from the reference model is considered as abnormal condition, moreover if the fault effect is bounded by the span of $\rho_{f}$, the fault will be compensated. However, the $L P V$ controller must increase its conservatism in order to take into account the uncertainty of the unknown fault, thus the overall controller performance becomes less effective for each fault.

\section{CONCLUSIONS}

A Fault Tolerant Control System (FTCS) of a semiactive suspension in a Quarter of Vehicle $(Q \circ V)$ model is proposed. The proposed FTCS, considered as an active scheme, is based on a Fault Detection and Isolation (FDI) module which accommodates the fault on the controller reconfiguration by using the Linear Parameter-Varying $(L P V)$ control theory. Two scheduling parameters are included in the $L P V$ control design, one incorporates the nonlinear behavior (saturation and semiactiveness) of a Magneto-Rheological $(M R)$ damper and the other is used for the fault accommodation; since both scheduling variables depend on the measured signal $\left(\dot{z}_{\text {def }}\right)$, they can be calculated. The scheduling parameter that accommodates the malfunction is provided by the FDI system as a ratio between the output of a reference model and the process. The reference model is the process in normal operating conditions. A comparison between the FTCS and a conventional $L P V$ controller shows the effectiveness of FTCS for accommodating sensor faults.

Simulation results in the frequency response show that the fault deteriorates the comfort $(54 \%)$ when this is not accommodated, mainly at low frequencies (0-5 Hz); the comfort index of the conventional controller overshoots the recommended limit. Similarly, the FTCS shows lower acceleration in the sprung mass in almost all frequency automotive range. On the other hand, the road holding index shows that the FTCS can increase the safety $(33 \%)$ in the vehicle when a soft fault in the $\dot{z}_{\text {def }}$ sensor occurs, while the suspension deflection index represents a $39 \%$ of improvement in the lifetime of the damper, specially at low frequencies.

\section{REFERENCES}

Abdullah, A. and Zribi, M. (2009). Model Reference Control of LPV Systems. J. Franklin I., 346, 854-871.

Blanke, M., Kinnaert, M., Lunze, J., and Staroswiecki, M. (2006). Diagnosis and Fault-Tolerant Control. Springer, $2^{\text {nd }}$ Ed., Berlin.

Bosche, J., Hajjaji, A., and Rabhi, A. (2009). Actuator Fault-Tolerant Control for Vehicle Dynamics. In t th $^{\text {th }}$ Safeprocess, Spain, 1103-1108.

Chamseddine, A. and Noura, H. (2008). Control and Sensor Fault Tolerance of Vehicle Active Suspension. IEEE Trans. on Control Systems Tech., 16(3), 416-433.

Do, A., Spelta, C., Savaresi, S., Sename, O., Dugard, L., and Delvecchio, D. (2010). An LPV Control Approach for Comfort and Suspension Travel Improvements of Semi-Active Suspension Systems. In $49^{\text {th }}$ IEEE Conf. on Decision and Control, USA, 5560-5565.

Dong, X., Yu, M., Liao, C., and Chen, W. (2010). Comparative Research on Semi-Active Control Strategies for Magneto-rheological Suspension. Nonlinear Dynamics, 59, 433-453.

Fischer, D. and Isermann, R. (2004). Mechatronic Semiactive and Active Vehicle Suspensions. Control Eng. Practice, 12, 1353-1367.

Gáspár, P., Szabó, Z., and Bokor, J. (2010). LPV Design of Fault-tolerant Control for Road Vehicles. In Conf. on Control and Fault Tolerant Systems, France, 807-812.

Jiang, J. (2005). Fault-tolerant Control Systems -An Introductory Overview. ACTA Automatica, 31, 161174.

Miyasato, Y. (2006). Model Reference Adaptive Control of Polytopic LPV Systems - An Alternative Approach to Adaptive Control. In Int. Symp. on Intelligent Control, Germany, 2012-2017.

Patton, R. (1997). Fault Tolerant Control: The 1997 Situation. In $3^{\text {rd }}$ Safeprocess, England, 1033-1055.

Poussot-Vassal, C., Sename, O., Dugard, L., Gáspár, P., Szabó, Z., and Bokor, J. (2008). A New Semi-active Suspension Control Strategy through LPV Technique. Control Eng. Practice, 16, 1519-1534.

Rodrigues, M., Theilliol, D., Aberkane, S., and Sauter, D. (2007). Fault Tolerant Control Design for Polytopic LPV Systems. Int. J. AMCS, 17(1), 27-37.

Savaresi, S. and Spelta, C. (2007). Mixed Sky-hook and ADD: Approaching the Filtering Limits of a Semi-active Suspension. J. of Dynamic Systems, Measurement and Control, 169, 382-392.

Sloth, C., Esbensen, T., and Stoustrup, J. (2010). Active and Pasive Fault-Tolerant LPV Control of Wind Turbines. In American Control Conf., USA, 4640-4646.

Spelta, C., Savaresi, S., and Fabbri, L. (2010). Experimental Analysis of a Motorcycle Semi-active Rear Suspension. Control Eng. Practice, 18, 1239-1250.

Vargas-Martínez, A., Puig, V., Garza-Castanón, L., and Morales-Menendez, R. (2010). MRAC $+H_{\infty}$ Fault Tolerant Control for Linear Parameter Varying Systems. In Sys Tol 2010, France, 94-99.

Yetendje, A., Seron, M., and Dona, J.D. (2007). Diagnosis and Actuator Fault Tolerant Control in Vehicle Active Suspension. In ICIAFS'07, Melbourne, VIC, 153-158.

Zhang, Y. and Jiang, J. (2008). Bibliographical Review on Reconfigurable Fault-tolerant Control Systems. Annual Reviews in Control, 32, 229-252. 